CLINICAL STUDY

\title{
Glucocorticoid replacement therapy and pharmacogenetics in Addison's disease: effects on bone
}

\author{
Kristian Løvås $^{1,2}$, Clara G Gjesdal ${ }^{3,4}$, Monika Christensen ${ }^{5}$, Anette B Wolff ${ }^{1,6}$, Bjørg Almås ${ }^{5}$, Johan Svartberg ${ }^{7,8}$, \\ Kristian J Fougner ${ }^{9,10}$, Unni Syversen ${ }^{9,10}$, Jens Bollerslev ${ }^{11,12}$, Jan A Falch ${ }^{11,13}$, Penelope J Hunt ${ }^{14}$, \\ V Krishna K Chatterjee ${ }^{15}$ and Eystein S Husebye ${ }^{1,2}$ \\ ${ }^{1}$ Institute of Medicine, University of Bergen, 5020 Bergen, Norway. ${ }^{2}$ Department of Medicine, Haukeland University Hospital, 5021 Bergen, Norway, \\ ${ }^{3}$ Institute of Social Sciences in Medicine, University of Bergen, Bergen, Norway, ${ }^{4}$ Department of Rheumatology, ${ }^{5}$ The Hormone Laboratory and ${ }^{6}$ Centre for \\ Clinical Genetics and Molecular Medicine, Haukeland University Hospital, 5021 Bergen, Norway, ${ }^{7}$ Department of Medicine, University Hospital of North \\ Norway, Tromsø, Norway, ${ }^{8}$ Institute of Clinical Medicine, University of Tromsø, Tromsø, Norway, ${ }^{9}$ Department of Medicine, St Olavs Hospital, \\ Trondheim, Norway, ${ }^{10}$ Insitute of Cancer Research and Molecular Medicine, Norwegian University of Science and Technology, Trondheim, Norway, \\ ${ }^{11}$ Faculty of Medicine, University of Oslo, Oslo, Norway, ${ }^{12}$ Section of Endocrinology, Rikshospitalet University Hospital, Oslo, Norway, ${ }^{13}$ Department of \\ Endocrinology, Aker University Hospital, Oslo, Norway, ${ }^{14}$ Department of Endocrinology, Christchurch Hospital, Canterbury, New Zealand and \\ ${ }^{15}$ Department of Medicine, University of Cambridge, Cambridge, UK \\ (Correspondence should be addressed to K Løvås; Email: kristian.lovas@med.uib.no)
}

\begin{abstract}
Context: Patients with primary adrenal insufficiency (Addison's disease) receive more glucococorticoids than the normal endogenous production, raising concern about adverse effects on bone.

Objective: To determine i) the effects of glucocorticoid replacement therapy on bone, and ii) the impact of glucocorticoid pharmacogenetics.

Design, setting and participants: A cross-sectional study of two large Addison's cohorts from Norway $(n=187)$ and from UK and New Zealand $(n=105)$.

Main outcome measures: Bone mineral density (BMD) was measured; the Z-scores represent comparison with a reference population. Blood samples from 187 Norwegian patients were analysed for bone markers and common polymorphisms in genes that have been associated with glucocorticoid sensitivity.

Results: Femoral neck BMD Z-scores were significantly reduced in the patients (Norway: mean -0.28 (95\% confidence intervals (CI) - 0.42, - 0.16); UK and New Zealand: -0.21 (95\% CI -0.36 , -0.06)). Lumbar spine Z-scores were reduced (Norway: $-0.17(-0.36,+0.01)$; UK and New Zealand: $-0.57(-0.78,-0.37))$, and significantly lower in males compared with females $(P=0.02)$. The common P-glycoprotein (ABCB1) polymorphism C3435T was significantly associated with total $\mathrm{BMD}(\mathrm{CC}$ and $\mathrm{CT}>\mathrm{TT} P=0.015)$, with a similar trend at the hip and spine.

Conclusions: BMD at the femoral neck and lumbar spine is reduced in Addison's disease, indicating undesirable effects of the replacement therapy. The findings lend support to the recommendations that $15-25 \mathrm{mg}$ hydrocortisone daily is more appropriate than the higher conventional doses. A common polymorphism in the efflux transporter $P$-glycoprotein is associated with reduced bone mass and might confer susceptibility to glucocorticoid induced osteoporosis.
\end{abstract}

European Journal of Endocrinology $160993-1002$

\section{Introduction}

Primary adrenal insufficiency (Addison's disease) is a rare disease mainly caused by autoimmune destruction of the adrenal cortex. The treatment is a replacement of mineralocorticoids and glucocorticoids (1), but conventional replacement doses replenish more glucocorticoids than are normally produced $(2,3)$. The serum cortisol profile obtained with present medication features peaks, troughs and abolished circadian pattern (4-6). Studies have reproducibly shown impairment of health-related quality of life in these patients, indicating that the replacement therapy is not optimal (7-9).

Glucocorticoids accelerate reduction in bone mass by inhibition of osteoblast activity, stimulation of osteoclast activity and inhibition of intestinal vitamin $\mathrm{D}$ dependent calcium absorption. Furthermore, patients with adrenal insufficiency lack adrenal androgens, possibly conferring additional risk of osteoporosis. It is not known whether osteoporosis is more common in patients with Addison's than in the general population. A series of small studies in Addison's disease have shown 
inconsistent correlation between bone mineral density (BMD) and disease duration, glucocorticoid type and dose; the main findings are summarized in Table 1 (10-16). Most of these studies found reduced mean BMD that was not statistically significant, but none of the studies were sufficiently powered to reliably determine these effects. Gurnell et al. published the largest trial so far of adrenal androgens in Addison's disease suggesting that 12 months DHEA replacement slightly but significantly increased BMD at the femoral neck, but not at other skeletal sites (9).

Little is known about the individual susceptibility to glucocorticoid-induced osteoporosis (GIOP), neither in patients with Addison's disease nor in general. Single nucleotide polymorphisms (SNPs) in genes that govern glucocorticoid metabolism and sensitivity (Fig. 1) are likely to confer some of this susceptibility. Multiple SNPs with possible functional effects exist in these genes (17-20), but most of the variants are rare and would require large patient populations to investigate. Therefore, we chose to include common SNPs with likely functional effects.

Glucocorticoids are substrates for the efflux transporter P-glycoprotein (encoded by the ATP-binding cassette B1 (ABCB1) gene) (21-24), and common polymorphic variation in this gene, particularly three common SNPs in linkage disequilibrium, associates with altered pharmacokinetics and pharmacodynamics of numerous drugs $(17,18,25,26)$. Only a few studies have addressed the association between $A B C B 1$ polymorphisms and clinical outcome of glucocorticoid therapy (27-29). Among the common SNPs, rs1045642 has been most consistently associated with reduced function of P-glycoprotein; we hypothesized that this SNP could lead to increment in intracellular cortisol levels, since less is pumped out of the cell, and thus increased risk of GIOP.

Variable levels of the co-chaperone FK506 binding protein (FKBP51; encoded by FKBP5) determines glucocorticoid sensitivity $(30,31)$. The common SNP rs1360780 may be associated with increased sensitivity

Table 1 Previous studies of bone mineral density in Addison's disease.

\begin{tabular}{|c|c|c|c|c|c|}
\hline & & \multicolumn{2}{|c|}{ Men } & \multicolumn{2}{|c|}{ Women } \\
\hline & & $n$ & BMD & $n$ & BMD \\
\hline Devolagear et al. (10) & 1987 & 12 & Ns & 21 & $\downarrow^{b}$ \\
\hline Florkowski et al. (11) & 1994 & 5 & Ns & 9 & $\downarrow$ \\
\hline Zelissen et al. (12) & 1994 & 31 & $\downarrow$ & 60 & Ns \\
\hline Valero et al. (13) & 1994 & 8 & Ns & 22 & $\downarrow^{b}$ \\
\hline Braatvedt et al. (14) & 1999 & 19 & $\downarrow^{a}$ & 10 & Ns \\
\hline Jodar et al. (15) & 2003 & 6 & Ns & 19 & Ns \\
\hline Arlt et al. (16) & 2006 & 7 & Ns & 8 & $\mathrm{Ns}$ \\
\hline
\end{tabular}

$\downarrow$, significantly reduced and Ns, not significantly different from normal.

a Confined to men with low testosterone.

${ }^{b}$ Confined to post-menopausal women.

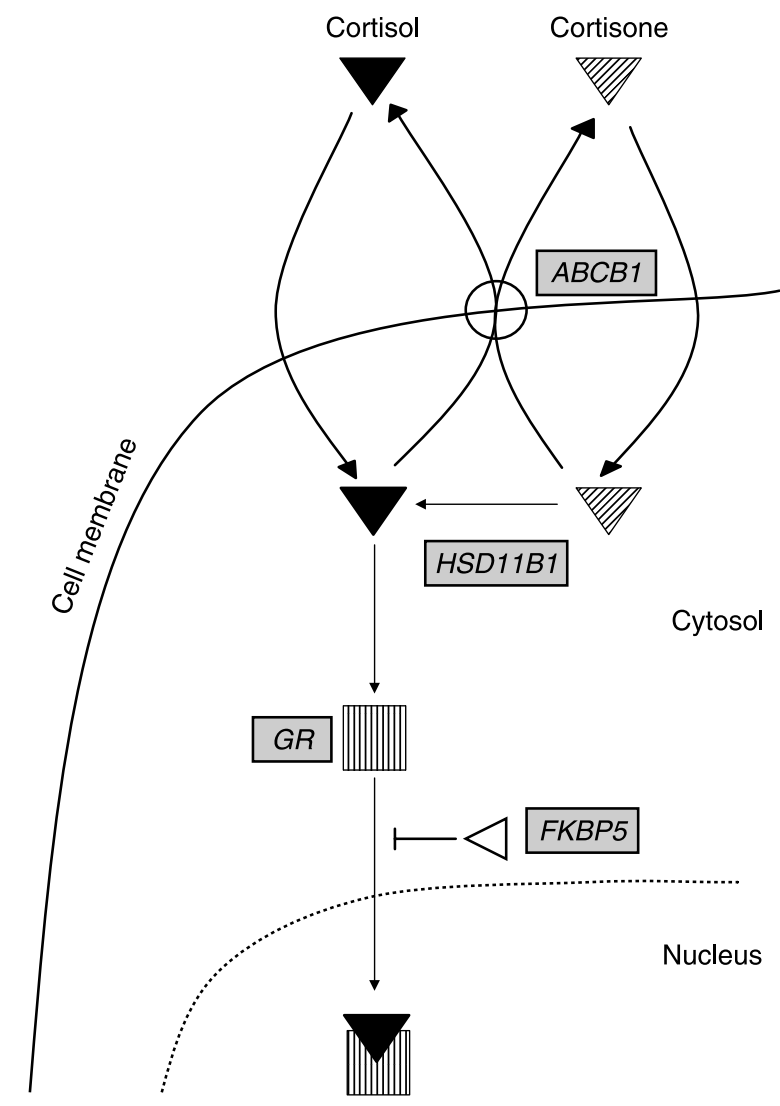

Figure 1 Selected genes ( $A B C B 1$, ATP binding cassette $B 1$; FKBP5, FK506 binding protein 51; HSD11B1, $11 \beta$-hydroxysteroid dehydrogenase type $1 ; G R$, glucocorticoid receptor) with common polymorphisms that are hypothesized to influence glucocorticoid action.

to glucocorticoids $(19,32,33)$; hence we postulated increased risk of GIOP in carriers of this SNP. Variable activity of the enzyme 11 $\beta$-hydroxysteroid dehydrogenase type 1 (11 $\beta$-HSD1) is associated with the risk of osteoporosis, possibly due to its role in peripheral activation of cortisone to cortisol (34). Reduced activity of this enzyme is associated with the common SNP rs12086634 in HSD11B1 (20), which could possibly protect against GIOP. A few SNPs in the glucocorticoid (GR) gene confer variation in sensitivity to glucocorticoids; rs6195 is associated with enhanced sensitivity and rs6189/rs6190 with reduced sensitivity. These SNPs are likely to influence the risk for GIOP, but they are relatively rare variants with allele frequencies below 5\% (35).

The aims of this study were i) to evaluate whether the conventional replacement of glucocorticoids in two large cohorts of patients with Addison's disease is associated with reduced bone mass, and ii) to test the hypothesized effects on BMD and bone markers of selected common gene polymorphisms. 


\section{Materials and methods}

\section{Subjects and design}

A Norwegian cohort $(n=187)$ was recruited from the Norwegian Registry of Addison's disease. Inclusion criteria were aged 30 years or more and had verified Addison's disease, as documented by low serum cortisol and simultaneously elevated ACTH. Adrenal insufficiency after adrenalectomy and congenital adrenal hyperplasia were exclusion criteria. The patients were assessed at five Norwegian university clinics in the period November 2004-November 2006, according to a standardized protocol. Adjusted glucocorticoid dosage was calculated as hydrocortisone equivalents $(0.8$, 5 and 20 times the doses of cortisone acetate, prednisolone and dexamethasone respectively) per $\mathrm{kg}$ body weight. BMD was measured in all patients, and spinal X-rays performed in patients aged 50 years or more. After overnight medication fast of glucocorticoids a serum sample was obtained. DNA was available from a bio-bank for most patients. The patients gave written informed consent before entering the study, which was approved by the western Norway ethics committee for medical research.

A cohort of Addison's disease patients from UK and New Zealand (UK/NZ, $N=105$ ), aged $18-65$ years with disease duration of at least 1 year was previously studied in a 12-month trial of DHEA replacement in primary adrenal insufficiency (9); baseline clinical data and BMD measurements (obtained before 2003) were made available for this study. The diagnosis was substantiated by documented hypocortisolemia, and raised serum ACTH (or hyperpigmentation). Exclusion criteria were pregnancy, past personal history of hormone-dependent malignancy and any intercurrent significant medical or psychiatric condition.

Control populations The Lunar database was used as reference for BMD measurements, as a previous study demonstrated that BMD in the femur and total body of the subjects in this database complied well with the general Norwegian population (36). The results of dual X-ray absorptiometry (DXA) measurements and vertebral morphometry (spinal X-rays) were compared with the results of the European vertebral osteoporosis study in which normative data from Norwegian and UK populations were available $(37,38)$. Eighty-nine blood donors (47 males and 42 females) aged 20-69 were used as controls for the bone marker analyses.

\section{Measurements}

Bone mineral density $\mathrm{BMD}$ at the femoral neck, total hip, lumbar spine and total body was measured by DXA, according to a standardized protocol. In the Norwegian cohort four study centres applied Lunar scanners and one centre used a Hologic scanner. The UK and New
Zealand cohort was assessed with Hologic scanners. To standardize the measurements between the centres the hip and spine scores of all the patients assessed with Hologic scanners were transformed to Lunar scores by standard equations (39). Z-scores were calculated for all the patients using regression equations from the Lunar database (36), as this database was found to be representative for the Norwegian population (36). Total body BMD Z-scores were analyzed as given by the scanners without any adjustment. The within-day and between-day coefficients of variation (CV) were below $2 \%$ for all the scanners tested. In vivo crosscalibration of the Lunar DXA scanners at three of the study sites was undertaken in 15 volunteers, showing only minor variation (40); and no significant difference compared with the Hologic scanner with phantom measurements. All patients who had DXA measurements performed more than 3 years previously were assessed for longitudinal Z-score changes.

Spinal X-rays Standardized spinal X-rays were taken for morphometric analysis of all patients 50 years or older in the Norwegian cohort, and interpreted according to the algorithm developed by McCloskey et al. (41).

Biochemical analyses Serum samples were stored under light-protected conditions at $-80{ }^{\circ} \mathrm{C}$. All bone markers were analyzed in the same laboratory in duplicates and in one batch. The bone marker assays were analyzed with ELISAs. For the analysis of serum osteocalcin, we used an assay from Nordic Bioscience Diagnostics (Herlev, Denmark), which measures both intact osteocalcin and the N-terminal mid-region fragment of osteocalcin. The mean variation between pairs of samples measured was $4.1 \%$. Inter-assay $\mathrm{CV}$ was $6.9 \%$ in the low range and $2.3 \%$ in the high range. CrossLaps (Nordic Bioscience Diagnostics) measures the degradation product of C-terminal telopeptides of type-I collagen (CTX). Mean variation between sample pairs was $12.8 \%$. Inter-assay CV was $24.2 \%$ in the low range and $7.8 \%$ in the high range. Bone-specific alkaline phosphatase (ALP) was determined with an assay from Quidel Corporation (San Diego, CA, USA). The mean variation between the pairs of samples was $5.0 \%$, inter-assay $\mathrm{CV}$ was $7.0 \%$ in the low range and $2.6 \%$ in the high range.

Genetic analyses We elected to study genes that are anticipated to influence glucocorticoid sensitivity, i.e. ABCB1, FKBP5, HSD11B1 and GR (Fig. 1). Multiple SNPs with possible functional effects exist in these genes, but most of the variants are rare and would require large patient populations to investigate; therefore, in this study, we included SNPs with allele frequencies $>0.1$, except $G R$ for which well validated SNPs are found at lower frequencies. Genotyping was 
performed by allelic discrimination analysis using the 7900HT fast real-time PCR system and Taqman allelic discrimination assays (Applied Biosystems, Foster City, CA, USA) for the SNPs: rs1045642 (ABCB1), rs1360780 (FKBP5), rs12086634 (HSD11B1) and rs6195 (GR). The assays were performed following the recommendations from the supplier although less volume of the reagents was used (only $2 \mu \mathrm{l}$ dried DNA with the addition of $2 \mu \mathrm{l}$ mastermix containing enzyme, primers and probes). Twenty of the DNAs were run twice and the genotypes reproduced for all. The coupled SNPs rs6189/rs6190 (GR) were analyzed by PCR and DNA sequencing of exon 2 by using the forward primer 5'-GCTGCCTCTTACTAATCGGATCA-3' and the reverse primer 5'-GCTGCGCATTGCTTACTGAG-3'.

\section{Statistical analysis}

BMD is expressed by Z-scores, which represent age and gender-adjusted SDS, which are presented with 95\% confidence intervals (CI). CI different from zero indicates Z-scores statistically different from the reference population. The influence of age, gender, disease duration, cumulative glucocorticoid use, concomitant endocrine diseases (diabetes mellitus type 1 and/or autoimmune thyroid disease), current smoking, family history and genotypes on the Z-scores was analysed by linear regression analysis in a backward-stepwise fashion. For women premature hypogonadism was also entered as a variable in the regression analysis. Power calculations indicated that $\sim 250$ patients would be required to exclude mean effects on Z-scores of 0.25 with significance level 0.05 and power 0.80 .
The inclusion of two independent cohorts counteracts the limitation of statistical power in each cohort.

Comparison of BMD and bone markers between the genotypes was done in both a recessive model for the variant alleles (CC and CT versus TT (variant), Student's t-test), and a co-dominant model (CC-CT-TT, linear regression analysis) including the significant determinants as identified in the regression analysis above. The $P$ values are given unadjusted for multiple analyses (three genes $\times$ four skeletal sites). However, the Z-scores at the different skeletal sites within individuals correlate strongly; thus a Bonferroni correction for three independent analyses is reasonable. For analysis of gene associations, the power to detect minor differences was limited; hence, the results must be viewed as observations rather than evidence.

\section{Results}

\section{Patients}

Characteristics of the 187 Norwegian patients and the 105 patients from UK and New Zealand are shown in Table 2. The frequency of self-reported concomitant endocrine diseases was as expected. The Norwegian patients were older and had longer duration of Addison's disease than the patients from UK and New Zealand. The Norwegian patients mostly used cortisone acetate, whereas almost all the patients from UK and New Zealand were on hydrocortisone replacement. For seven out of the 15 patients on bisphosphonate therapy pre-treatment DXA scans were available, which were used in the further analysis.

Table 2 Characteristics and replacement therapy mean (s.D.) of patients with Addison's disease in Norway and UK and New Zealand.

\begin{tabular}{|c|c|c|c|c|c|c|}
\hline & \multicolumn{3}{|c|}{ Norwegian } & \multicolumn{3}{|c|}{ UK and New Zealand } \\
\hline & Women & Men & Total & Women & Men & Total \\
\hline Age (year) & $53(14)$ & $52(16)$ & $53(15)$ & $47(10)$ & $44(10)$ & $46(10)$ \\
\hline Disease duration (year) & $17(14)$ & 19 (13) & $18(13)$ & $14(10)$ & $15(12)$ & $14(11)$ \\
\hline \multicolumn{7}{|l|}{$\begin{array}{l}\text { Replacement therapy } \\
\text { Glucocorticoid dose }\end{array}$} \\
\hline $\mathrm{HC}$ equivalents ${ }^{\mathrm{a}}(\mathrm{mg})$ & $31.5(11)$ & $33.2(11)$ & $32.1(11)$ & $24.7(7.2)$ & $29.1(9.4)$ & $26.5(8.4)$ \\
\hline HC equivalent/body weight (mg/kg) & $0.47(0.1)$ & $0.41(0.1)$ & $0.45(0.1)$ & $0.36(0.1)$ & $0.36(0.1)$ & $0.36(0.1)$ \\
\hline \multicolumn{7}{|l|}{ Glucocorticoid type } \\
\hline Hydrocortisone (\%) & 1.6 & 0.0 & 1.1 & 95.2 & 93.0 & 94.3 \\
\hline Cortisone acetate (\%) & 98.4 & 98.4 & 98.4 & 1.6 & 2.3 & 1.9 \\
\hline Prednisolone (\%) & 0.8 & 1.6 & 2.1 & 3.2 & 2.3 & 2.9 \\
\hline Dexamethasone (\%) & 0.8 & 4.8 & 1.1 & 0.0 & 2.3 & 1.0 \\
\hline \multicolumn{7}{|l|}{ Concomitant endocrine diseases } \\
\hline APS1 (\%) & 3 & 3 & 3 & NR & NR & NR \\
\hline \multicolumn{7}{|l|}{ Antiresorptive therapy } \\
\hline Bisphosphonates $(n)$ & 11 & 2 & 13 & 1 & 1 & 2 \\
\hline Oestrogen replacement $(n)$ & 18 & - & 18 & 22 & - & 22 \\
\hline
\end{tabular}

APS1, autoimmune polyglandular syndrome type 1 . NR, not reported.

${ }^{\text {a }} \mathrm{HC}$ equivalents, cortisone acetate estimated at $80 \%$ of hydrocortisone $(\mathrm{HC})$ potency. 


\section{Bone mineral density}

Femoral neck BMD was significantly lower in the patients than in the reference database; as expressed by mean Z-scores as illustrated in Fig. 2A (Norway: -0.28 (95\% CI $-0.42,-0.16)$; UK and New Zealand: -0.21 (95\% CI $-0.36,-0.06)$ ). Total hip Z-scores were significantly reduced in the Norwegian cohort $(-0.29(-0.46$, $-0.15)$ ), but not in the UK and New Zealand cohort $(0.09(-0.26,+0.27))$. Lumbar spine Z-scores in the patients were lower than in the Lunar reference population (Fig. 2B; UK and New Zealand: -0.57 $(-0.78,-0.37)$; Norway: $-0.17(-0.36,+0.01))$, and significantly lower in males compared with females $(P=0.02)$. Total body BMD was only available for the Norwegian patients (Table 3), which was not significantly different from normal.

In Norwegian patients, the Z-scores at the femoral neck (Fig. 3, $P=0.02)$, total hip $(P<0.001)$ and total body $(P=0.02)$, but not those at lumbar spine $(P=0.27)$, were significantly associated with weightadjusted glucocorticoid dose. These associations were not explained by variation in weight, and persisted when patients taking synthetic glucocorticoids (prednisolone or dexamethasone, $n=10$ ) were omitted
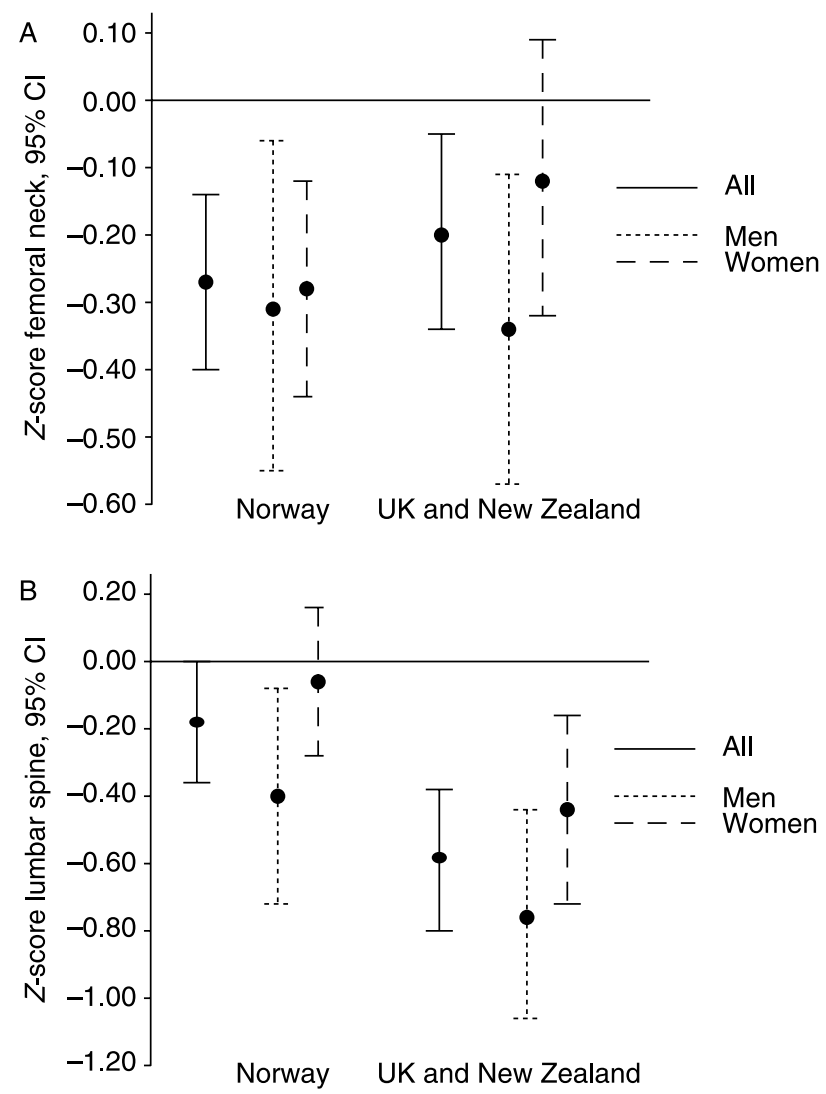

Figure 2 BMD Z-scores in Addison's disease patients from Norway $(n=187)$ and UK and New Zealand $(n=105)$. (A) Femoral neck. (B) Lumbar spine.

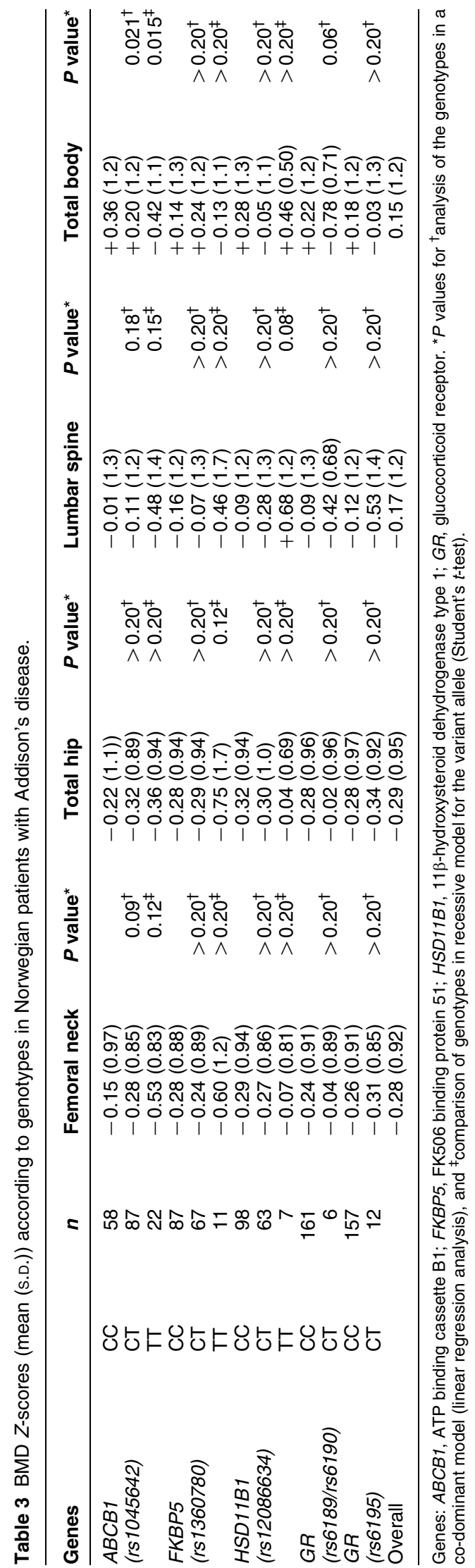

www.eje-online.org 


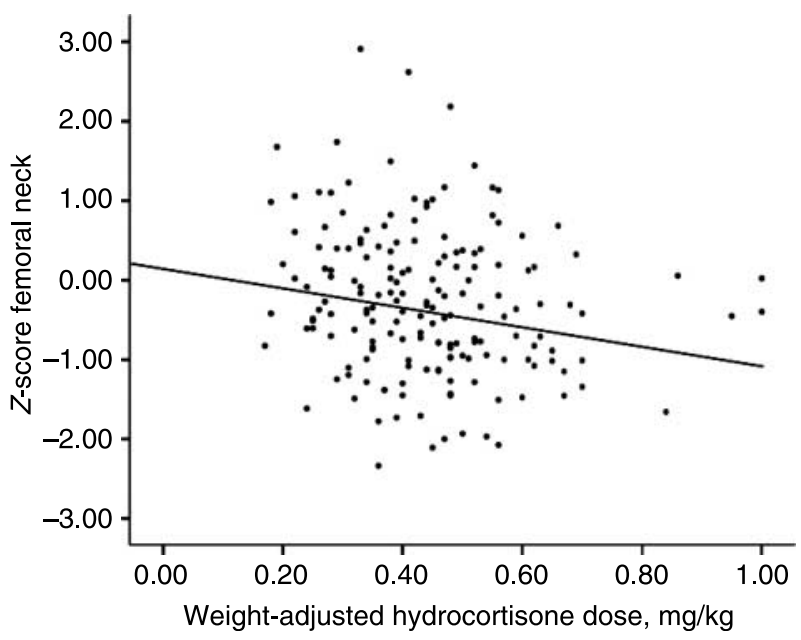

Figure 3 Correlation between weight-adjusted glucocorticoid dose (hydrocortisone equivalents per kg per day) and femoral neck $Z$-scores in Norwegian patients.

from the analysis. The Z-scores in the UK and New Zealand cohort did not correlate with glucocorticoid dose at any site. The patients taking synthetic glucocorticoids had lower BMD compared with those taking only natural glucocorticoids (cortisone acetate or hydrocortisone, $n=282$ ), but the differences were not statistically significant (mean Z-scores: femoral neck -0.67 vs $-0.24(P=0.13)$, total hip -0.59 vs -0.13 $(P=0.14)$, lumbar spine -0.93 vs $-0.30(P=0.10)$ and total body -0.47 vs $+0.17(P=0.19))$.

Disease duration had no impact on the Z-scores at any location. Longitudinal data obtained from 47 patients (mean observation interval 8 years (s.D. 2.7)) showed no change in femoral neck Z-scores in those without antiresorptive therapy $(n=40$, mean annual change $+0.006(-0.004,+0.017))$. In those receiving bisphosphonates or hormone replacement therapy (HRT), femoral neck Z-score tended to increase $(n=7$, mean annual change +0.035 , CI $(-0.014,+0.084))$.

Concomitant endocrine diseases such as diabetes mellitus type 1 or autoimmune thyroid disease did not correlate with Z-scores at any site in either patient population. In the cross-sectional analysis, the Z-scores were marginally lower in smokers (22\% of patients) than in non-smokers, and marginally higher in women on HRT than in those without; at all locations, however, none of these differences were statistically significant (data not shown). The BMD of the women having had premature gonadal insufficiency $(7 \%$ of the female patients) did not differ from the women with a history of normal gonadal function (data not shown).

\section{Spinal X-rays}

$\mathrm{X}$-rays of the thoracolumbar spine were obtained from 84 patients of 50 years and older in the Norwegian cohort (mean age 63.0 years). Fourteen patients (16.8\%, CI (8.7-24.7), men: 4/29 (13.8\%), mean age 62.4 years; women 10/55 (18.1\%), mean age 66.3 years) had one or more vertebral fractures. The frequency of patients with vertebral fractures was not different from that reported in a Norwegian reference population (men: $15.7 \%$, mean age 65.3 years; women: $19.2 \%$, mean age 65.4 years) (38).

\section{Genotypes and BMD}

DNA was available from 171 of the Norwegian patients. All the SNPs were in Hardy-Weinberg equilibrium. The BMD Z-scores for the ABCB1, FKBP5, HSD11B1 and GR genotypes are shown in Table 3. There was a significant correlation between the ABCB1 rs1045642 genotype and total body Z-score, and this correlation was similar in the patients that were assessed with the Hologic scanner as those assessed with Lunar scanners. The correlation was significant both in a recessive model (CC (wildtype) and CT versus TT (variant) genotypes, (Student's $t$-test, $P=0.015$ )) as well as in a co-dominant model (CC versus CT versus TT, linear regression analysis, $P=0.021$ ), but not in a dominant model (CC versus CT and TT, Student's $t$-test, $P=0.15$ ). The same pattern between $A B C B 1$ genotypes and Z-scores was observed at the other skeletal regions, although statistically non-significant. Similar results were obtained if weight-adjusted glucocorticoid dose was entered into the model and when patients taking synthetic glucocorticoids were excluded from the analyses (data not shown).

\section{Biochemical analyses}

Sera were available from 168 of the Norwegian patients. The PTH concentration was normal (mean $4.2 \mathrm{nmol} / \mathrm{l}$, s.D. 2.7; five patients with APS1 and hypoparathyroidism were excluded). The levels of osteocalcin, bone-specific ALP and CTX in patients and controls are shown in Table 4. Osteocalcin and CTX levels were higher in patients than in controls; whereas bone-specific ALP was similar in the two groups. None of these parameters correlated with weight-adjusted glucocorticoid dose. Compared with homozygous FKBP5 rs1360780 CC (wildtype) carriers, there was a trend towards lower levels of bone formation and resorption markers in individuals carrying the FKBP5 TT (variant) genotype. No statistical differences were demonstrated between $A B C B 1$ or HSD11B1 genotypes.

\section{Discussion}

We here demonstrate that BMD at the femoral neck and lumbar spine is slightly but significantly lower than normal in patients with Addison's disease. The patients 
Table 4 Bone markers in Norwegian Addison patients and controls, and according to genotypes.

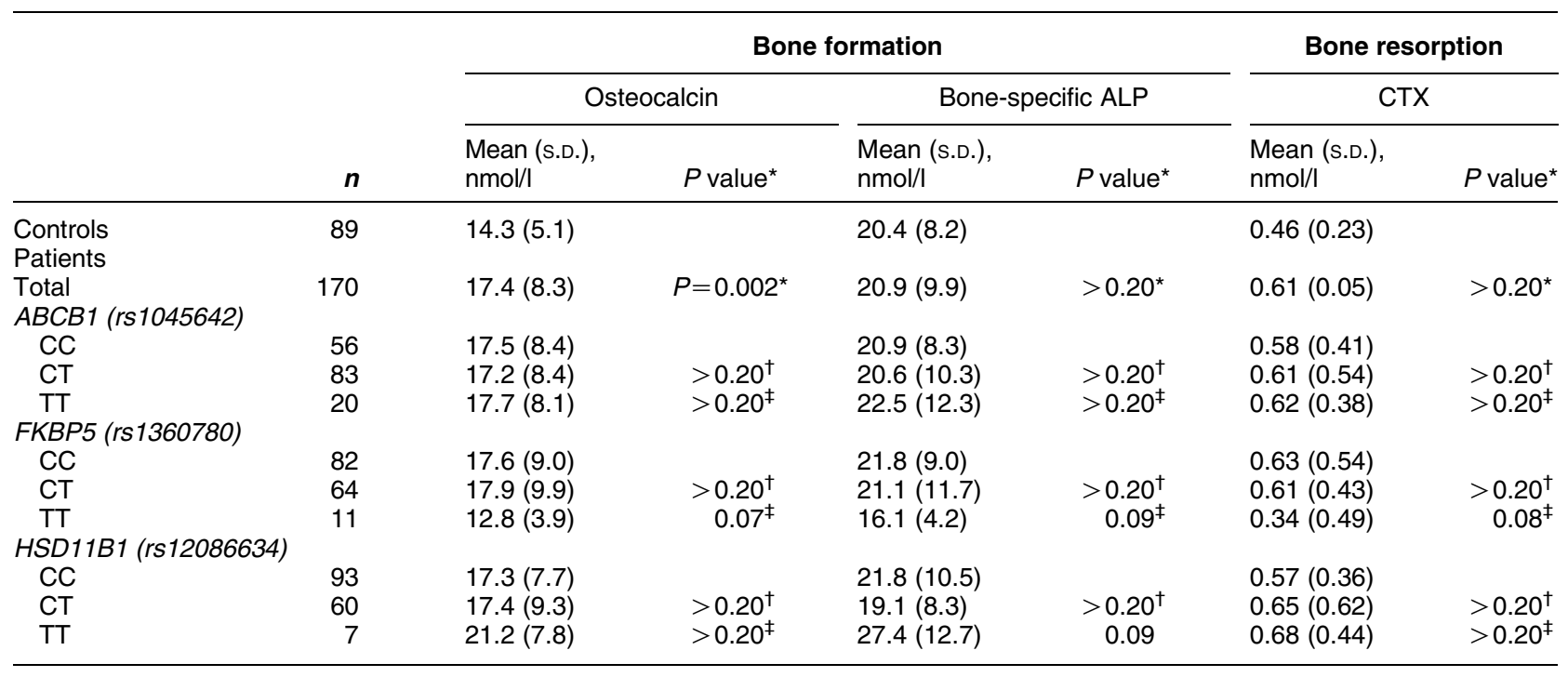

CTX, C-terminal telopeptides of Type-I collagen. Genes: ABCB1, ATP Binding cassette B1; FKBP5, FK506 binding protein 51; HSD11B1, $11 \beta$-hydroxysteroid dehydrogenase type 1. $P$ values for *comparison of patients versus controls, and for ${ }^{\dagger}$ analysis of the genotypes in a co-dominant model (linear regression analysis), and ${ }^{\ddagger}$ comparison of genotypes in recessive model for the variant allele (Student's $t$-test).

in this study received mean replacement doses $26.5 \mathrm{mg}$ hydrocortisone or $40.1 \mathrm{mg}$ of cortisone acetate divided into two or three daily doses, which is higher than the recent suggestions that 15-20 mg hydrocortisone daily may be more appropriate $(1,4-6,42)$. The inverse association between glucocorticoid dosage and BMD in the Norwegian cohort, which was also reported in the two largest previous studies $(12,14)$, indicates that even mild over-replacement of glucocorticoids has adverse effects on bone. Lack of association with duration of replacement therapy complies well with observations that glucocorticoids rapidly reduce BMD without further progression of bone loss (43). Notably, BMD may underestimate fracture risk, as glucocorticoids not only affect bone mineralization but also connective tissue (43). Furthermore, glucocorticoid excess most likely inhibits appositional bone growth, reducing bone diameter which is an important determinant of bone strength (44). On the other hand, we did not find increased prevalence of vertebral fractures in the patients, but the population was too small to rule this out with sufficient power.

We found that the few patients on prednisolone or dexamethasone had lower BMD than those on cortisone acetate or hydrocortisone. These differences were not statistically significant, but a similar association has been found in previous studies $(12,15,45)$. Synthetic glucocorticoids may have favourable pharmacokinetic properties (i.e. longer half-lives) compared with the natural glucocorticoids, but they have pharmacodynamics properties (i.e. more potent metabolic effects) that render them less suitable in replacement therapy (46). Prospective trials comparing various glucocorticoid regimens are certainly needed, and novel replacement modes such as modified-release tablets and continuous s.c. hydrocortisone infusion should be considered $(47,48)$.

The clinical relevance of adrenal androgen depletion in Addison's disease has been much debated. The recent 12 months DHEA replacement study by Gurnell et al. found minor, but significant improvement of BMD at the femoral neck, but no effect on any other location. All the other DHEA replacement trials have been small and short-term, which have shown inconsistent results on bone markers (49-51). Thus, DHEA replacement may improve BMD and ultimately reduce fracture risk, but more studies are needed.

Although the adverse effects of glucocorticoid replacement doses may be limited, genetic variation is likely to influence the individual risk of reduced bone mass. The number of patients in this study allowed only for analysis of common SNPs in selected genes, but rare variants in these and other genes are likely to have greater impact on glucocorticoid sensitivity. We found that the common polymorphism rs1045642 in the efflux transporter P-glycoprotein $(A B C B 1)$ is significantly associated with total body BMD and with a similar pattern at all the skeletal sites studied. The observed associations between BMD and glucocorticoid pharmacogenetics are remarkable, given the large normal variability in BMD. Rs1045642 is associated with impaired function of the P-glycoprotein efflux pump $(25,26)$, which could lead to increment in intracellular cortisol levels. This is the first populationbased study of association between ABCB1 genotype and glucocorticoid effects on bone. We speculate that 
this association could be even more pronounced in pharmacological treatment with synthetic glucocorticoids, as the P-glycoprotein shows higher affinity for both prednisolone and dexamethasone than for cortisol (23). Addison's disease might be perceived as a model for glucocorticoid effects on bone since these patients lead normal lives and have less confounding factors than other patients treated with glucocorticoids.

Only a few studies have addressed the association between $A B C B 1$ polymorphisms and clinical outcome of glucocorticoid therapy. Paediatric heart transplant patients homozygous for the rs1045642 wildtype allele were significantly more steroid dependent 1 year after transplantation than those carrying one or two variant alleles (27). Both this and the results of our investigation are in keeping with the experimental studies $(21,22,52)$, and support the hypothesis that reduced activity of the P-glycoprotein efflux pump expose the target cells to higher concentrations of glucocorticoids. Conversely, a study of steroid-responsive nephrotic syndrome in children showed longer time to remission in patients homozygous for $A B C B 1$ haplotypes containing the variant allele (29). Another study found an association between the variant allele and decreased risk of osteonecrosis of the femoral head after kidney transplantation (28). However, these are complex diseases with complex treatments involving immunosuppressants that are also substrates for $P$-glycoprotein. Furthermore, inconsistent results might relate to drug interactions, as $A B C B 1$ expression is induced by a number of compounds by activation of the nuclear receptor steroid and xenobiotic receptor (53).

The glucocorticoid receptor co-chaperone FKBP51 (encoded by FKBP5) plays a pivotal role for glucocorticoid sensitivity (30). A common SNP in FKBP5 associates with frequency of depressive episodes and response to antidepressant therapy, and with risk of post-traumatic stress disorder in adults who had experienced childhood abuse $(19,32,33)$; both conditions might relate to cerebral glucocorticoid sensitivity. We did not observe significant associations between FKBP5 genotype and sensitivity in bone as evaluated by BMD and bone markers.

Variable activity of the enzyme $11 \beta$-HSD1 is associated with risk of osteoporosis, due to its role in peripheral activation of cortisone to cortisol (34). Reduced activity of this enzyme is associated with a SNP in HSD11B1 (20). We found higher BMD and higher levels of bone formation markers in the few homozygote carriers of this SNP than in carriers of the wildtype, but the differences were not statistically significant. We found no individuals homozygous for any of the GR polymorphisms and no evident trends for the few heterozygous carriers.

Although this is the largest study of bone effects in Addison's disease so far the sample size and the use of reference databases for BMD rather than age- and sex matched controls limits the statistical power of the analyses. This is particularly true for the analysis of the genotype effects, which must be viewed as observations rather than evidence. Different glucocorticoids as used in these cohorts might also have different impact on bone. We found no elevation of PTH levels in the Norwegian patients, and a previous analysis of 30 patients showed normal vitamin D levels (Falch, unpublished data, 1994). Still, vitamin D status is a possible confounding factor, as other factors such as thyroid status and sex hormone levels.

We conclude that BMD at the femoral neck and lumbar spine was slightly but significantly lower than normal in patients with Addison's disease. Such undesirable metabolic effects indicate that the recent recommendations of lower glucocorticoid replacement doses are appropriate. The common rs1045642 polymorphism in the efflux transporter P-glycoprotein is associated with BMD in patients with Addison's disease, and might be important for susceptibility to glucocorticoid induced osteoporosis. Glucocorticoid pharmacogenomics is likely to explain some of the variation in the effects of glucocorticoids on bone, and genotyping of the ABCB1, FKBP5, HSD11B1 and GR genes might become part of future pharmacogenomic individual tailoring of both replacement and pharmacological therapy with glucocorticoids.

\section{Declaration of interest}

There are no conflicts of interest.

\section{Funding}

The study was supported by grants from EU FP7 (grant no 201167 , Euradrenal), The Regional Health Authorities in western Norway (Helse Vest), and NIHR Cambridge Biomedical Research Centre.

\section{Acknowledgements}

Technical assistance at the various study centres is greatly appreciated.

\section{References}

1 Arlt W \& Allolio B. Adrenal insufficiency. Lancet $2003 \mathbf{3 6 1}$ 1881-1893.

2 Kerrigan JR, Veldhuis JD, Leyo SA, Iranmanesh A \& Rogol AD. Estimation of daily cortisol production and clearance rates in normal pubertal males by deconvolution analysis. Journal of Clinical Endocrinology and Metabolism 199376 1505-1510.

3 Esteban NV, Loughlin T, Yergey AL, Zawadzki JK, Booth JD, Winterer JC \& Loriaux DL. Daily cortisol production rate in man determined by stable isotope dilution/mass spectrometry. Journal of Clinical Endocrinology and Metabolism $1991 \mathbf{7 2}$ $39-45$.

4 Howlett TA. An assessment of optimal hydrocortisone replacement therapy. Clinical Endocrinology 199746 263-268. 
5 Peacey SR, Guo CY, Robinson AM, Giles MA, Eastell R \& Weetman AP. Glucocorticoid replacement therapy: are patients over treated and does it matter? Clinical Endocrinology $1997 \mathbf{4 6}$ 255-261.

6 Crown A \& Lightman S. Why is the management of glucocorticoid deficiency still controversial: a review of the literature. Clinical Endocrinology 200563 483-492.

7 Løvås K, Loge $\mathrm{JH}$ \& Husebye ES. Subjective health status in Norwegian patients with Addison's disease. Clinical Endocrinology $200256581-588$.

8 Hahner S, Loeffler M, Fassnacht M, Weismann D, Koschker AC, Quinkler M, Decker O, Arlt W \& Allolio B. Impaired subjective health status in 256 patients with adrenal insufficiency on standard therapy based on cross-sectional analysis. Journal of Clinical Endocrinology and Metabolism $2007923912-3922$.

9 Gurnell EM, Hunt PJ, Curran SE, Conway CL, Pullenayegum EM, Huppert FA, Compston JE, Herbert J \& Chatterjee VK. Long-term DHEA replacement in primary adrenal insufficiency: a randomized, controlled trial. Journal of Clinical Endocrinology and Metabolism 200893 400-409.

10 Devogelaer JP, Crabbe J \& Nagant De Deuxchaisnes C. Bone mineral density in Addison's disease: evidence for an effect of adrenal androgens on bone mass. BMJ 1987 294 798-800.

11 Florkowski CM, Holmes SJ, Elliot JR, Donald RA \& Espiner EA. Bone mineral density is reduced in female but not male subjects with Addison's disease. New Zealand Medical Journal 1994107 52-53.

12 Zelissen PM, Croughs RJ, Van Rijk PP \& Raymakers JA. Effect of glucocorticoid replacement therapy on bone mineral density in patients with Addison disease. Annals of Internal Medicine 1994 120 207-210.

13 Valero MA, Leon M, Ruiz Valdepenas MP, Larrodera L, Lopez MB, Papapietro K, Jara A \& Hawkins F. Bone density and turnover in Addison's disease: effect of glucocorticoid treatment. Bone and Mineral 199426 9-17.

14 Braatvedt GD, Joyce M, Evans M, Clearwater J \& Reid IR. Bone mineral density in patients with treated Addison's disease. Osteoporosis International 199910 435-440.

15 Jodar E, Valdepenas MP, Martinez G, Jara A \& Hawkins F. Longterm follow-up of bone mineral density in Addison's disease. Clinical Endocrinology 200358 617-620.

16 Arlt W, Rosenthal C, Hahner S \& Allolio B. Quality of glucocorticoid replacement in adrenal insufficiency: clinical assessment vs timed serum cortisol measurements. Clinical Endocrinology $2006 \mathbf{6 4} 384-389$.

17 Marzolini C, Paus E, Buclin T \& Kim RB. Polymorphisms in human MDR1 (P-glycoprotein): recent advances and clinical relevance. Clinical Pharmacology and Therapeutics 200475 13-33.

18 Sakaeda T. MDR1 genotype-related pharmacokinetics: fact or fiction? Drug Metabolism and Pharmacokinetics $200520391-414$.

19 Binder EB, Salyakina D, Lichtner P, Wochnik GM, Ising M, Putz B, Papiol S, Seaman S, Lucae S, Kohli MA, Nickel T, Kunzel HE, Fuchs B, Majer M, Pfennig A, Kern N, Brunner J, Modell S, Baghai T, Deiml T, Zill P, Bondy B, Rupprecht R, Messer T, Kohnlein O, Dabitz H, Bruckl T, Muller N, Pfister H, Lieb R, Mueller JC, Lohmussaar E, Strom TM, Bettecken T, Meitinger T, Uhr M, Rein T, Holsboer F \& Muller-Myhsok B. Polymorphisms in FKBP5 are associated with increased recurrence of depressive episodes and rapid response to antidepressant treatment. Nature Genetics 200436 1319-1325.

20 Draper N, Walker EA, Bujalska IJ, Tomlinson JW, Chalder SM, Arlt W, Lavery GG, Bedendo O, Ray DW, Laing I, Malunowicz E, White PC, Hewison M, Mason PJ, Connell JM, Shackleton CH \& Stewart PM. Mutations in the genes encoding 11beta-hydroxysteroid dehydrogenase type 1 and hexose-6-phosphate dehydrogenase interact to cause cortisone reductase deficiency. Nature Genetics 200334 434-439.

21 Ueda K, Okamura N, Hirai M, Tanigawara Y, Saeki T, Kioka N, Komano T \& Hori R. Human P-glycoprotein transports cortisol, aldosterone, and dexamethasone, but not progesterone. Journal of Biological Chemistry 1992267 24248-24252.
22 Karssen AM, Meijer OC, Van Der Sandt IC, Lucassen PJ, De Lange EC, De Boer AG \& De Kloet ER. Multidrug resistance $P$-glycoprotein hampers the access of cortisol but not of corticosterone to mouse and human brain. Endocrinology 2001 142 2686-2694.

23 Yates CR, Chang C, Kearbey JD, Yasuda K, Schuetz EG, Miller DD, Dalton JT \& Swaan PW. Structural determinants of P-glycoproteinmediated transport of glucocorticoids. Pharmaceutical Research 200320 1794-1803.

24 Pariante CM. The role of multi-drug resistance $P$-glycoprotein in glucocorticoid function: studies in animals and relevance in humans. European Journal of Pharmacology 2008583 263-271.

25 Kimchi-Sarfaty C, Oh JM, Kim IW, Sauna ZE, Calcagno AM, Ambudkar SV \& Gottesman MM. A 'silent' polymorphism in the MDR 1 gene changes substrate specificity. Science $2007 \mathbf{3 1 5}$ 525-528.

26 Salama NN, Yang Z, Bui T \& Ho RJ. MDR1 haplotypes significantly minimize intracellular uptake and transcellular $P$-gp substrate transport in recombinant LLC-PK1 cells. Journal of Pharmaceutical Sciences 200695 2293-2308.

27 Zheng H, Webber S, Zeevi A, Schuetz E, Zhang J, Lamba J, Bowman P \& Burckart GJ. The MDR1 polymorphisms at exons 21 and 26 predict steroid weaning in pediatric heart transplant patients. Human Immunology 200263 765-770.

28 Asano T, Takahashi KA, Fujioka M, Inoue S, Okamoto M, Sugioka N, Nishino H, Tanaka T, Hirota Y \& Kubo T. ABCB1 C3435T and G2677T/A polymorphism decreased the risk for steroid-induced osteonecrosis of the femoral head after kidney transplantation. Pharmacogenetics 200313 675-682.

29 Wasilewska A, Zalewski G, Chyczewski L \& Zoch-Zwierz W. MDR-1 gene polymorphisms and clinical course of steroid-responsive nephrotic syndrome in children. Pediatric Nephrology 200722 44-51.

30 Vermeer H, Hendriks-Stegeman BI, Verrijn Stuart AA, Van BuulOffers SC \& Jansen M. A comparison of in vitro bioassays to determine cellular glucocorticoid sensitivity. European Journal of Endocrinology 2004150 41-47.

31 Woodruff PG, Boushey HA, Dolganov GM, Barker CS, Yang YH, Donnelly S, Ellwanger A, Sidhu SS, Dao-Pick TP, Pantoja C, Erle DJ, Yamamoto KR \& Fahy JV. Genome-wide profiling identifies epithelial cell genes associated with asthma and with treatment response to corticosteroids. PNAS $2007 \mathbf{1 0 4} 15858-15863$.

32 Binder EB, Bradley RG, Liu W, Epstein MP, Deveau TC, Mercer KB, Tang Y, Gillespie CF, Heim CM, Nemeroff CB, Schwartz AC, Cubells JF \& Ressler KJ. Association of FKBP5 polymorphisms and childhood abuse with risk of posttraumatic stress disorder symptoms in adults. Journal of the American Medical Association 2008299 1291-1305.

33 Lekman M, Laje G, Charney D, Rush AJ, Wilson AF, Sorant AJ, Lipsky R, Wisniewski SR, Manji H, Mcmahon FJ \& Paddock S. The FKBP 5-gene in depression and treatment response-an association study in the sequenced treatment alternatives to relieve depression (STAR*D) Cohort. Biological Psychiatry 200863 1103-1110.

34 Cooper MS. Sensitivity of bone to glucocorticoids. Clinical Science 2004107 111-123.

35 Van Rossum EF, Russcher H \& Lamberts SW. Genetic polymorphisms and multifactorial diseases: facts and fallacies revealed by the glucocorticoid receptor gene. Trends in Endocrinology and Metabolism 200516 445-450.

36 Gjesdal CG, Aanderud SJ, Haga HJ, Brun JG \& Tell GS. Femoral and whole-body bone mineral density in middle-aged and older Norwegian men and women: suitability of the reference values. Osteoporosis International 200415 525-534.

37 Lunt M, Felsenberg D, Reeve J, Benevolenskaya L, Cannata J, Dequeker J, Dodenhof C, Falch JA, Masaryk P, Pols HA, Poor G, Reid DM, Scheidt-Nave C, Weber K, Varlow J, Kanis JA, O’Neill TW \& Silman AJ. Bone density variation and its effects on risk of vertebral deformity in men and women studied in thirteen European centers: the EVOS Study. Journal of Bone and Mineral Research 199712 1883-1894. 
38 O'Neill TW, Felsenberg D, Varlow J, Cooper C, Kanis JA \& Silman AJ. The prevalence of vertebral deformity in European men and women: the European vertebral osteoporosis study. Journal of Bone and Mineral Research 199611 1010-1018.

39 Genant HK, Grampp S, Gluer CC, Faulkner KG, Jergas M, Engelke K, Hagiwara S \& Van Kuijk C. Universal standardization for dual X-ray absorptiometry: patient and phantom crosscalibration results. Journal of Bone and Mineral Research 19949 1503-1514.

40 Omsland TK, Emaus N, Gjesdal CG, Falch JA, Tell GS, Forsen L, Berntsen GK \& Meyer HE. In vivo and in vitro comparison of densitometers in the NOREPOS study. Journal of Clinical Densitometry $200711276-282$.

41 McCloskey EV, Spector TD, Eyres KS, Fern ED, O'Rourke N, Vasikaran S \& Kanis JA. The assessment of vertebral deformity: a method for use in population studies and clinical trials. Osteoporosis International 19933 138-147.

42 Barbetta L, Dall'Asta C, Re T, Libè R, Costa E \& Ambrosi B. Comparison of different regimens of glucocorticoid replacement therapy in patients with hypoadrenalism. Journal of Endocrinological Investigation 200528 632-637.

43 Canalis E, Mazziotti G, Giustina A \& Bilezikian JP. Glucocorticoidinduced osteoporosis: pathophysiology and therapy. Osteoporosis International 200718 1319-1328.

44 Seeman E \& Delmas PD. Bone quality - the material and structural basis of bone strength and fragility. New England Journal of Medicine $20063542250-2261$.

45 Suliman AM, Freaney R, Smith TP, McBrinn Y, Murray B \& McKenna TJ. The impact of different glucocorticoid replacement schedules on bone turnover and insulin sensitivity in patients with adrenal insufficiency. Clinical Endocrinology 200359 380-387.

46 Diederich S, Eigendorff E, Burkhardt P, Quinkler M, Bumke-Vogt C, Rochel M, Seidelmann D, Esperling P, Oelkers W \& Bähr V. 11 betahydroxysteroid dehydrogenase types 1 and 2: an important pharmacokinetic determinant for the activity of synthetic mineralo- and glucocorticoids. Journal of Clinical Endocrinology and Metabolism 200287 5695-5701.
47 Newell-Price J, Whiteman M, Rostami-Hodjegan A, Darzy K, Shalet S, Tucker GT \& Ross RJ. Modified-release hydrocortisone for circadian therapy: a proof-of-principle study in dexamethasonesuppressed normal volunteers. Clinical Endocrinology $2008 \mathbf{6 8}$ $130-135$.

48 Løvås K \& Husebye ES. Continuous subcutaneous hydrocortisone infusion in Addison's disease. European Journal of Endocrinology 2007157 109-112.

49 Arlt W, Callies F, Van Vlijmen JC, Koehler I, Reincke M, Bidlingmaier M, Huebler D, Oettel M, Ernst M, Schulte HM \& Allolio B. Dehydroepiandrosterone replacement in women with adrenal insufficiency. New England Journal of Medicine 1999341 1013-1020.

50 Løvås K, Gebre-Medhin G, Trovik TS, Fougner KJ, Uhlving S, Nedrebø BG, Myking OL, Kämpe O \& Husebye ES. Replacement of dehydroepiandrosterone in adrenal failure: no benefit for subjective health status and sexuality in a 9-month, randomized, parallel group clinical trial. Journal of Clinical Endocrinology and Metabolism 200388 1112-1118.

51 Hunt PJ, Gurnell EM, Huppert FA, Richards C, Prevost AT, Wass JA, Herbert J \& Chatterjee VK. Improvement in mood and fatigue after dehydroepiandrosterone replacement in Addison's disease in a randomized, double blind trial. Journal of Clinical Endocrinology $2000854650-4656$.

52 Farrell RJ, Menconi MJ, Keates AC \& Kelly CP. P-glycoprotein-170 inhibition significantly reduces cortisol and ciclosporin efflux from human intestinal epithelial cells and T lymphocytes. Alimentary Pharmacology \& Therapeutics 200216 1021-1031.

53 Miki Y, Suzuki T, Tazawa C, Blumberg B \& Sasano H. Steroid and xenobiotic receptor (SXR), cytochrome P450 3A4 and multidrug resistance gene 1 in human adult and fetal tissues. Molecular and Cellular Endocrinology 2005231 75-85.

Received 25 February 2009

Accepted 9 March 2009 